\title{
Incision Site in Manual Small Incision Cataract Surgery in Case of Preoperative Direct Astigmatism
}

\author{
Nganga Ngabou Charles Geraud Fredy ${ }^{1,2 *}$ (D), Makita Chantal1,2, Onka Vissimy ${ }^{1,3}$, \\ Messe Ambia Koulimaya Reinette ${ }^{2}$, Diatewa Benedicte ${ }^{2}$, Gombe Eyissa ${ }^{1}$, \\ Bouhelo Olandzobo Francine ${ }^{2}$ \\ ${ }^{1}$ University Marien Ngouabi, Brazzaville, The Republic of Congo \\ ${ }^{2}$ Department of Ophthalmology, University Hospital of Brazzaville, Brazzaville, The Republic of Congo \\ ${ }^{3}$ Clinic Ophthalmology, Brazzaville, The Republic of Congo \\ Email: ^fredygeraud@gmail.com, chantalmakita@gmail.com, gombenzieyissa@gmail.com, onka.vissimy@gmail.com, \\ mchkr_n@yahoo.fr, bene.diat@gmail.com,gombenzieyissa@gmail.com, Olanfrancine@yahoo.fr
}

How to cite this paper: Fredy, N.N.C.G., Chantal, M., Vissimy, O., Reinette, M.A.K., Benedicte, D., Eyissa, G. and Francine, B.O. (2020) Incision Site in Manual Small Incision Cataract Surgery in Case of Preoperative Direct Astigmatism. Case Reports in Clinical Medicine, 9, 47-52.

https://doi.org/10.4236/crcm.2020.91008

Received: December 19, 2019

Accepted: January 12, 2020

Published: January 15, 2020

Copyright (c) 2020 by author(s) and Scientific Research Publishing Inc. This work is licensed under the Creative Commons Attribution International License (CC BY 4.0).

http://creativecommons.org/licenses/by/4.0/

\begin{abstract}
We compared surgically induced astigmatism (SIA) by a superior incision with a temporal incision in manual small incision cataract surgery (MSICS), in patients with bilateral direct (regular) preoperative corneal astigmatisms. Patients and method: We carried out a prospective study from July $1^{\text {st }} 2018$ to September $30^{\text {th }} 2019$ in the department of ophthalmology at the University Hospital of Brazzaville. Keratometric readings were recorded before surgery to assess preoperative corneal astigmatisms. Keratometric evaluation was done 45 days post-operatively. Patients were followed 90 days after surgery in order to assess the healing of the surgical site. The surgically induced astigmatism (SIA) is the difference in the magnitude vectors between the preoperative and postoperative astigmatism. The result was positive if the postoperative astigmatism was greater than the preoperative astigmatism and negative if the postoperative astigmatism was less than the preoperative astigmatism. Results: Our study sample included 48 eyes from 24 patients, including 24 operated on temporal incision and 24 in superior incision. The average SIA for superior incisions was $0.33 \pm 1.55$ diopters (D), versus $0.33 \pm 1.44$ for temporal incisions. For superior incisions the SIA was 0.81 for astigmatisms lower than $2 \mathrm{D}$, against $0.16 \mathrm{D}$ for the temporal incisions. On the other hand, for preoperative astigmatisms greater than $2 \mathrm{D}$, the surgically induced astigmatism was $-0.62 \mathrm{D}$, marking a decrease in preoperative astigmatism for the superior incisions against an increase of $0.5 \mathrm{D}$ for the temporal incisions. The healing was delayed for the temporal incisions responsible for discomfort persisting beyond 45 days. Conclusion: The temporal incision had better re-
\end{abstract}


sults than the superior incision for astigmatisms lower than $2 \mathrm{D}$, and less good for astigmatisms higher than 2D. The temporal incision healed less well.

\section{Keywords}

Manual Small Incision Cataract Surgery, Direct Astigmatism, Surgically Induced Astigmatism

\section{Introduction}

Manual small incision cataract surgery (MSICS) is a surgical technique recommended for developing countries due to its lower technological requirement and these results close to those of phacoemulsification [1]. The difference with phacoemulsification is mainly dominated by the surgically induced astigmatism (SIA) more important in the MSICS because of its wider incision [2].

In order to reduce occurrence of SIA, the authors propose to make temporal incisions by MSICS [3] [4] [5]. Temporal incisions generate less SIA because of the distance of this site from the visual axis, and the eyelid blink tends to create a drag on the incision [4], but also because of the predominance of reverse (irregular) astigmatisms in the elderly [6] most affected by cataracts. In these patients with reverse astigmatism, SIA is opposed to preexisting astigmatism with a tendency to reduce the latter [7]. For direct (regular) astigmatisms, it would rather be the upper incisions which would oppose preexisting astigmatism and are considered as generating the strongest SIA.

To date, no study has specifically addressed direct astigmatism and its incision site during MSICS.

The objective of this study is to determine the incision site generating less SIA during MSICS in case of direct astigmatisms.

\section{Patients and Methods}

\subsection{Patients}

We carried out a prospective study in the ophthalmology department of the University Hospital of Brazzaville. In our study, all patients with bilateral direct astigmatism who had cataract surgery on both eyes during the period from July 1, 2018 to June 30, 2019 and who were followed 90 days after surgery were recruited.

\subsection{Methods}

The patients selected underwent preoperative keratometry before surgery, highlighting direct corneal astigmatisms and evaluating the power of these astigmatisms.

The patients were then operated on using the MSICS technique, one eye with a superior incision and the other with a temporal incision. The interval between 
the two surgeries ranged from 7 to 15 days. The choice of incision site for the first eye was taken at random, while for the second eye it was a deduction.

A postoperative keratometry for each eye was performed on the 45th day postoperative, in order to determine postoperative astigmatism.

The surgically induced astigmatism (SIA) was calculated by the difference in the magnitude vectors between the preoperative and postoperative astigmatism. The result was positive if the postoperative astigmatism was greater than the preoperative astigmatism and negative if the postoperative astigmatism was less than the preoperative astigmatism.

Patients were followed until the 90th day to assess conjunctival scarring.

Informed consent was obtained from all patients.

Data analysis was performed with EPI INFO 7 software. The comparison tests used were those of $\mathrm{Chi}^{2}$ with a $95 \%$ confidence limit.

\section{Results}

Our sample included 48 eyes from 24 patients, including 24 operated on temporal incision and 24 in superior incision.

The mean age of the patients was $30.66 \pm 7.7$ years.

The sex ratio was 9.5.

The mean preoperative astigmatism for superior incisions was $2.37 \pm 1.18 \mathrm{di}$ opters (D), while the average postoperative astigmatism was $2.7 \pm 0.98 \mathrm{D}$.

Post-operative astigmatism for temporal incisions was $2.45 \pm 1.13 \mathrm{D}$, while mean post-operative astigmatism was $2.79 \pm 1.3 \mathrm{D}$.

The average SIA for superior incisions was $0.33 \pm 1.55 \mathrm{D}$, while it was $0.33 \pm$ 1.44D for temporal incisions.

As illustrated in Table 1, after superior incisions, SIA was 0.81D for astigmatisms lower than $2 \mathrm{D}$, against $0.16 \mathrm{D}$ after temporal incisions. On the other hand, for preoperative astigmatisms greater than $2 \mathrm{D}$, the surgically induced astigmatism was $-0.62 \mathrm{D}$, marking a decrease in preoperative astigmatism after superior incisions against an increase of $0.5 \mathrm{D}$ after temporal incisions.

Table 1. Variation of SIA according to whether the preoperative corneal astigmatism is greater or less than $2 \mathrm{D}$.

\begin{tabular}{cccc}
\hline & Incision site & Superior Incision & Temporal Incision \\
\hline & Effective & 16 & 12 \\
$\begin{array}{c}\text { Preoperative } \\
\text { Astigmatism }<2 \mathrm{D}\end{array}$ & Mean preoperative astigmatism & $1.62 \pm 0.53$ & $1.58 \pm 0.37$ \\
& Mean post operative astigmatism & $2.43 \pm 0.84$ & $1.75 \pm 0.21$ \\
& Surgically induced astigmatism & $0.81 \pm 1.37$ & $0.16 \pm 0.80$ \\
& Effective & 8 & 12 \\
Preoperative & Mean preoperative astigmatism & $3.87 \pm 0.4$ & $3.33 \pm 0.80$ \\
& Mean post operative astigmatism & $3.25 \pm 1.06$ & $3.83 \pm 1.21$ \\
& Surgically induced astigmatism & $-0.62 \pm 1.46$ & $0.50 \pm 1.91$ \\
\hline
\end{tabular}


We did not find any anomaly with the superior incision site, on the other hand $12.5 \%$ (Table 2) of the patients with temporal incision presented conjunctival anomalies, the comparison tests were not due to the small size of the sample.

The changes consisted of a radial orientation of the conjunctival vessels towards the cornea with hyperemia persisting beyond 45 days, responsible for variable discomfort. These lesions usually occurred in patients with preoperative pinguecula. All these conjunctival reactions disappeared before the 90th postoperative day.

\section{Discussion}

The surgically induced astigmatism (SIA) was calculated by the difference in the magnitude vectors between the preoperative and postoperative astigmatism as described by Reddy [8]. If this method does not take into account all the whole astigmatism actually induced by the incision, taking into account the neutralization of the preexisting astigmatism and the change of axes, as with the software available on the internet (SIA Calculator), it has the advantage of being simple and clear.

The average age of our patients was 30.66 years, it is a very young age, within the framework of a study on the cataract surgery, or generally the average age revolves around 60 years. This is due to the fact that astigmatism reverses with age [6]. There is more direct astigmatism in young subjects, and reverse in older subjects. As we work on direct astigmatisms, our patients are then younger. Cataracts being bilateral and less frequent at these ages, this also explains the small size of our sample.

The sex ratio of 0.95 shows an equitable distribution of this disease by sex.

The value of SIA was the same whether the patient was operated on by a superior incision or by a temporal incision. However, by separating these patients into two groups of preoperative astigmatisms (Table 1), it is found that patients with preoperative astigmatism less than or equal to $2 \mathrm{D}$ had a lower SIA after a temporal incision than superior incision. On the other hand, patients with a preoperative astigmatism greater than $2 \mathrm{D}$, saw their astigmatism increase by $0.5 \mathrm{D}$ with a temporal incision and decrease by $0.6 \mathrm{D}$ with a greater incision.

These results assume that patients with direct astigmatism below $2 \mathrm{D}$ should have a temporal incision and those with direct astigmatism above $2 \mathrm{D}$ should have a superior incision. Gokhale [4] had previously shown the advantage of the temporal incision for astigmatisms of $1.5 \mathrm{D}$ or less regardless of the axis of preoperative astigmatism. However, our small samples do not allow us to draw definitive conclusions.

Temporal incision gives a lower SIA for reverse astigmatisms and direct astigmatisms of less than 2D. This area is subjected to a more frequent occurrence of exposure lesions such as pterygium [9] compared to the superior incision site. It heals less quickly, sometimes with a dystrophic scar (Figure 1) and symptoms 
Table 2. Postoperative state of the conjunctiva depending on whether the patient is operated with a temporal incision or with a superior incision.

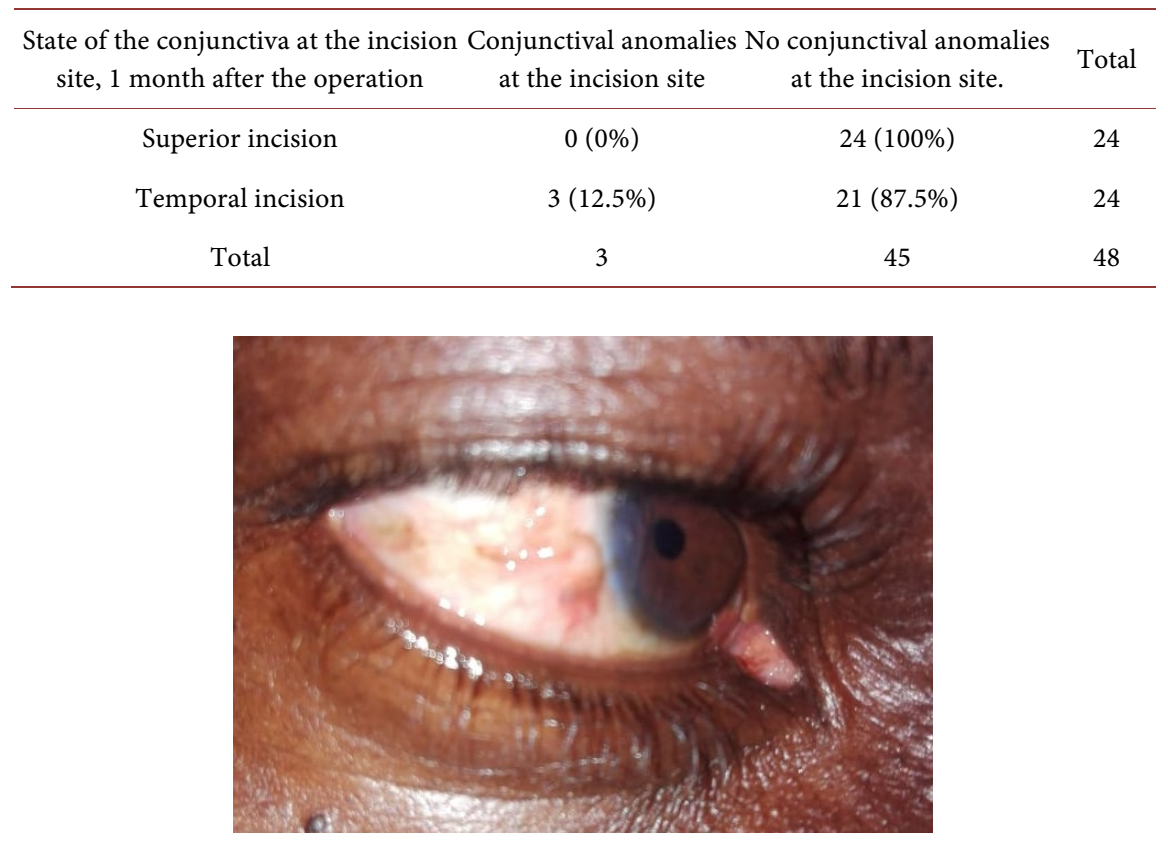

Figure 1. Dystrophic conjunctival cicatrization.

of eye tingling and hyperemia that persist beyond 45 days. These sequelae were associated with preoperative pinguecula, hence the need to take into account the state of the conjunctiva in the choice of the incision site, and to inform the patient of any postoperative reaction, especially in the case of associated temporal pterygium.

\section{Conclusion}

The temporal incision generates a lower SIA during MSICS for lower corneal astigmatisms lower than $2 \mathrm{D}$. For pre-operative astigmatisms greater than $2 \mathrm{D}$, the superior incision presented the best results. The temporal incision was associated with persistence of irritation on the incision area beyond 45 days.

\section{Conflicts of Interest}

The authors declare no conflicts of interest.

\section{References}

[1] Tabin, G., Chen, M. and Espandar, L. (2008) Cataract Surgery for the Developing World. Current Opinion in Ophthalmology, 19, 55-59. https://doi.org/10.1097/ICU.0b013e3282f154bd

[2] Gogate, P., Optom, J.J.B., Deshpande, S. and Naidoo, K. (2015) Meta-Analysis to Compare the Safety and Efficacy of Manual Small Incision Cataract Surgery and Phacoemulsification. Middle East African Journal of Ophthalmology, 22, 362-369. https://doi.org/10.4103/0974-9233.159763

[3] Malik, V.K., Kumar, S., Kamboj, R., Jain, C., Jain, K. and Kumar, S. (2012) Compar- 
ison of Astigmatism Following Manual Small Incision Cataract Surgery: Superior versus Temporal Approach. Nepalese Journal of Ophthalmology, 4, 54-58.

https://doi.org/10.3126/nepjoph.v4i1.5851

[4] Gokhale, N.S. and Sawhney, S. (2005) Reduction in Astigmatism in Manual Small Incision Cataract surgery through Change of Incision Site. Indian Journal of Ophthalmology, 53, 201-203. https://doi.org/10.4103/0301-4738.16684

[5] Arthur, E., Sadik, A.A., Kumah, Osae, E.A., Mireku, F.A., Asiedu, F.Y. and Kwame Ablordeppey, R. (2016) Postoperative Corneal and Surgically Induced Astigmatism Following Superior Approach Manual Small Incision Cataract Surgery in Patients with Preoperative Against-the-Rule Astigmatism. Journal of Ophthalmology, 2016, Article ID 9489036. https://doi.org/10.1155/2016/9489036

[6] Hayashi, K., Kawahara, S., Manabe, S. and Hirata, A. (2015) Changes in Irregular Corneal Astigmatism with Age in Eyes with and without Cataract Surgery. Investigative Ophthalmology \& Visual Science, 56, 7988-7998.

https://doi.org/10.1167/iovs.15-18058

[7] Lever, J. and Dahan, E. (2000) Opposite Clear Corneal Incisions to Correct Pre-Existing Astigmatism in Cataract Surgery. Journal of Cataract \& Refractive Surgery, 26, 803-805. https://doi.org/10.1016/S0886-3350(00)00378-3

[8] Reddy, B., Raj, A. and Singh, V.P. (2007) Site of Incision and Corneal Astigmatism in Conventional SICS versus Phacoemulsification. Annals of Ophthalmology (Skokie), 39, 209-216. https://doi.org/10.1007/s12009-007-0020-y

[9] Szwarcberg, J. and et Flament J. Ptérygion (2001) Encycl Méd Chir (Editions Scientifiques et Médicales Elsevier SAS, Paris, tous droits réservés). Ophtalmologie, 21-135-A-10, $12 \mathrm{p}$. 